\title{
A MODO DE PRESENTACIÓN
}

\section{As a Presentation}

José Luis CANO DE GARDOQUI GARCÍA

Profesor Titular

Universidad de Valladolid

E-mail: cano@fyl.uva.es

(1D http://orcid.org/0000-0002-9666-5036

\author{
J. Ricardo CHÁVEZ-MENDOZA \\ Profesor \\ UMSNH: Universidad Michoacana (México) \\ E-mail: ric.ch.m@gmail.com \\ (D) http://orcid.org/0000-0002-3907-976X
}

Cuando hace unos meses los que suscriben este texto introductorio propusimos para la revista Fonseca Journal of Communication un monográfico centrado en el fenómeno del Remake, convinimos en acordar un título que pudiera dar cabida a distintas formas de estudiar esta cuestión dentro de la multiplicidad de sus manifestaciones mediales. Para EL REMAKE, UNA PRÁCTICA EN EXPANSIÓN, tuvimos en cuenta el hecho cierto, tal y como señalábamos en la convocatoria, de que la aparición de nuevos formatos y soportes, incluidos los derivados de la denominada Revolución Digital, estaba llevando consigo un notable incremento de determinadas prácticas de incidencia significativa en la producción cultural, al generar o actualizar diversas modalidades de relaciones intertextuales.

Remakes, adaptaciones, revivals, reboots, spin offs, precuelas, secuelas, ciclos, series, homenajes, citas, plagios, franquicias y un largo etcétera posibilitan lo que aquí proponemos llamar -ampliando el dialogismo de Bajtín-, un plurilogismo, con reelaboraciones, ampliaciones y desbordamientos textuales que, en formas de interacción múltiples determinan el tejido de una nutrida red intertextual, plena de dinamismo.

Así pues, toda esta gama de modalidades conforma un atractivo campo de investigación que comprende desde lo más concreto - películas, series de televisión- hasta los ámbitos más globales de la reflexión teórico-analítica en la comunicación, la sociedad y la cultura.

Ciertamente conviene precisar que todos estos tipos de prácticas culturales no son necesariamente nuevos, pero es un hecho que se han visto ampliados y actualizados, con la consiguiente necesidad de profundizar su estudio. En el caso del remake cinematográfico, su práctica ha estado presente a lo largo de la historia del cine, desde sus inicios. 
Esta última reflexión resulta significativa, pues si, por una parte, los artículos que integran este monográfico reflejan en su aparato crítico un corpus teórico asentado en una bibliografía generada durante los últimos años; por la otra, el fenómeno del remake aparece revestido de un carácter diverso, susceptible de ser estudiado desde múltiples puntos de vista. De ello dan testimonio, no solo los trabajos que aquí se presentan, sino también los que, por diferentes circunstancias, en ocasiones debido a deslizamientos en el encuadramiento del fenómeno, han tenido que quedar fuera de la selección.

Las diferentes aproximaciones contenidas en este monográfico, pues, dan cuenta de una variedad representativa de preocupaciones, ya sea a través del estudio de casos concretos, del análisis de datos o de cartografías parciales de esta práctica en los ámbitos cinematográfico y televisivo.

Del total de siete artículos que los evaluadores ciegos han considerado favorablemente, hay una mayoría de textos dedicados al estudio del remake cinematográfico, así como un artículo que se ocupa de los remakes televisivos. En la opinión de quienes suscriben este texto, con las plataformas de video en internet (streaming video) como Netflix, y su creciente demanda de contenidos, el interés por los remakes en distintos medios no hará sino crecer.

En lo que estrictamente corresponde a este volumen, Isadora García Avis, en «La glocalización como rasgo definitorio del remake transcultural en televisión», aborda el tema partiendo de un elaborado repaso de distintas definiciones del término, primero desde el ámbito académico, luego desde la voz de los profesionales de la televisión, para adoptar el término de remake transcultural (entre una serie de opciones), y proponer que este tipo de remake implica una dinámica global/local, que puede designarse -siguiendo a Robertson (1995)- como «glocalización», la cual permite que el remake pueda adaptarse a los formatos y audiencias locales, sin perder de vista -enfatiza su autora- el papel de los componentes universales.

Con interés también en los remakes que implican producciones de un lugar distinto al de su texto de base, pero en el medio cinematográfico y decantándose por el término de remake transnacional, Miguel Fernández Labayen y Ana Martín Morán, en «Remakes transnacionales: dinámicas industriales y estéticas», explican las dinámicas mencionadas a partir de dos casos recientes de la cinematografía española: ¿Quién mató a Bambi? (Amodeo, 2013) y Kiki, el amor se hace (León, 2016), sendos remakes de Matando Cabos (Lozano, 2004) y The Little Death (Lawson, 2014), de nacionalidad mexicana y australiana respectivamente. Con el estudio de estos casos, los autores buscan perfilar un modelo transnacional de producción de remakes, en el que el género de la comedia, al que adscriben los casos en cuestión, jugaría un papel destacado. Su aproximación a los casos refiere tanto un conjunto de cambios operados al interior de la diégesis (personajes, situaciones, localización, referentes), como la opinión de agentes clave sobre las distintas fases del proceso de producción, incluida su interpretación del resultado comercial. El estudio de ambas dinámicas revela que, lejos de tratarse de producciones azarosas, existe una industria con estrategias para impulsar esta clase de producciones, más allá de las dinámicas de Hollywood.

Por su parte, Gloria Gomez-Escalonilla y Sofía Riesco Gadea, en su «Estudio de los remakes estrenados en España en el siglo XXI», después de una breve, pero pertinente reflexión sobre el término remake y su distinción con otros términos, dan cuenta de los remakes estrenados en España durante -prácticamente- lo que va del siglo XXI. Las investigadoras encuentran que, durante este periodo, se han estrenado en España 162 remakes, número que correlacionan con una serie de variables para indagar si hay algún periodo más recurrido, qué géneros destacan, la nacionalidad de las películas adaptadas, las casas productoras involucradas, los directores o los actores. Finalmente, se aportan 
datos sobre el presupuesto y la recaudación de los remakes. En suma, datos sobre los que se abre un amplio abanico de posibilidades interpretativas.

«Siete personajes en busca de un remake: De Kurosawa a Fuqua, pasando por Sturges» de José Lavín, Álvaro Jiménez Sánchez y Jesús María Navalpotro, se ocupa -al igual que otros artículos del monográfico- de películas de distinta nacionalidad, pero en este caso agregando un tercer remake para resaltar la variable temporal. Eligen, para ello, un caso emblemático, el de la película Los siete samuráis (Kurosawa, 1954), cuyos remakes, Los siete magnificos (Sturges, 1960) y Los 7 magnificos (Fuqua, 2016), se estudian a partir de tres categorías: trama, personajes y contexto. El análisis de lo anterior sirve a sus autores para puntualizar dónde radican las diferencias significativas, así como su correlación textual y contextual. Muestra de lo anterior es que algunos elementos, como los siete personajes referidos en el título, presentan en cada caso características particulares, no obstante, desempeñen básicamente las mismas funciones. Los samuráis, en la película de Kurosawa, pasan a ser los pistoleros en la de Sturges, hasta adquirir una configuración multiétnica, como representantes institucionales del orden, en la cinta de Fuqua.

«Remake, Historia e ideología: Hollywood y Adiós a las armas de Ernest Hemingway» de Alberto José Lena Ordoñez, trata de un minucioso análisis que, como en el caso anterior, también involucra a tres textos de diferente época, solo que en este caso se trata de un texto literario y dos versiones cinematográficas, la segunda, producida por David O. Selznick en 1957, a caballo entre la adaptación y el remake, puesto que a la vez que adapta la novela de Hemingway, tiene como referente permanente la primera versión de Borzage (1932). La propuesta de este artículo observa la manera en que tienen lugar una serie de transformaciones adaptativas, en las que no solo intervienen factores textuales, sino de manera muy importante aspectos ideológicos. Nada de ello ajeno a las circunstancias políticas de la época, mucho menos a la manera en que Hollywood adapta una historia para construir su versión de la Historia.

Siguiendo la línea de fenómenos intertextuales mixtos en los que participa el remake, se encuentra el artículo «La recuela: entre el remake y la secuela. El caso de Jurassic World» de Irene Raya Bravo, quien parte de un término en circulación como «recuela», para, a través del análisis de un caso citado por internautas como representativo, Jurassic World (2015), concluir sobre la manera en que se presentan estos componentes con relación a Jurassic Park (1993). En ese sentido, al ubicar la acción varios años después y dar continuidad temporal al universo ficcional, se estaría en los supuestos de la secuela; pero al mismo tiempo, en la medida que se reitera una arquitectura narrativa, tendría características de remake. Sin embargo, su autora concluye que formalmente al estar concebida en la continuidad de la secuela, no podría estrictamente clasificarse como un remake. La reflexión final gira en torno al término «recuela» y la necesidad de validar su pertinencia académica con estudios posteriores.

Finalmente, dentro del ámbito de la cinematografía argentina, Jorge Sala, en «Modos de reconciliación. Dos remakes de filmes de los sesenta en el cine argentino contemporáneo», reflexiona a partir de un par de casos destacados de las épocas convocadas, sobre la relación que los remakes y sus realizadores guardan con sus referentes históricos, para lograr una forma particular, a través de estrategias y modalidades distintas, de reconciliación con el pasado histórico, pero sobre todo con el pasado cinematográfico. El primer caso, Aniceto (2008), se trata de un autorremake donde su realizador, Leonardo Favio, logra la reconciliación sintética de dos etapas distintas -y usualmente vistas como contrapuestas- de su carrera filmográfica. Por su parte, Santiago Mitre, muta en su versión de La Patota (2015) de los elementos melodramáticos y de un contenido fuertemente religioso, presente en la 
versión de igual título de 1960, a abordar la problemática con medios del cine actual y dentro de un marco de valores laicos.

Como podrán dar cuenta las y los lectores no especializados, las perspectivas analíticas aquí presentadas, invitan a dejar de lado los juicios acusatorios contra el remake, para reflexionar más seriamente sobre esta práctica en expansión. Por su parte, las y los lectores especializados pueden encontrar sugerencias metodológicas y bibliográficas, datos, casos o reflexiones para discutir, ampliar o incluso refutar las propuestas presentadas. Al mismo tiempo, quedan abiertas a la discusión una serie de problemáticas que no aparecen representadas en el volumen, y que haría interesante, algunos años más adelante, una suerte de remake de este monográfico, el cual, seguramente, nos contará una historia de continuidades y rupturas.

No podemos cerrar esta presentación sin agradecer a todos los investigadores que acudieron a la convocatoria, así como a la revista Fonseca Journal of Communication, y muy especialmente a su directora, la Dra. Begoña Gutiérrez San Miguel.

\section{Fonseca, Journal of Communication}

